\title{
Causes and consequences of esterase 6 enzyme activity variation in pre-adult Drosophila melanogaster
}

\author{
JOHN G. OAKESHOTT*, MARLENE SAAD, ANNE Y. GAME \& MARION J. HEALY \\ CSIRO Division of Entomology, GPO Box 1700, Canberra, ACT, 2601, Australia
}

\begin{abstract}
We report heritable threefold differences in both larval and pupal esterase 6 activity among 17 isoallelic lines of $D$. melanogaster extracted from a natural population. The activity differences in the two stages are only weakly correlated with each other or with previously determined values for esterase 6 activity in adults of these lines. The pre-adult activity variation is also unrelated to polymorphisms among the lines for six esterase 6 allozymes and six restriction sites in a region encompassing the esterase 6 coding DNA and the first $\mathrm{kbp}$ of $5^{\prime}$ flanking DNA. However, two insertions, of 8.0 and $6.8 \mathrm{kbp}$, located about $1.4 \mathrm{kbp} 5^{\prime}$ of the esterase 6 coding region are associated with low activity in larvae and, to a lesser extent, in pupae, albeit not in adults. Restriction mapping reveals similarity between the $8.0 \mathrm{kbp}$ insert and the $7.4 \mathrm{kbp}$ retrotransposon 17.6. The differences in larval activity among lines are positively correlated with fitness as assessed from assays of pre-adult viability and development time but no significant associations between pupal esterase 6 activity and these measures are detected. Some effects of esterase 6 allozyme differences are also found for viability and development time but these effects could be explained by linkage disequilibrium between the $8.0 \mathrm{kbp}$ insert and the EST6-9 allozyme.
\end{abstract}

Keywords: Drosophila, esterase 6 activity, fitness differences, insertion polymorphism.

\section{Introduction}

Most empirical work on the level of enzyme variation and its adaptive significance has focused on structural polymorphisms detected by electrophoresis. Regulatory polymorphisms affecting the amounts of the enzymes have received less attention, largely because their phenotypes and inheritance are generally more complex. High levels of structural polymorphism have been documented in diverse species and evidence for high levels of regulatory polymorphism is also now accumulating, although the molecular bases of the latter have seldom been determined (but see Strand \& McDonald, 1989; Laurie et al., 1992 for notable exceptions). Despite exhaustive effort, little unambiguous evidence for an adaptive role for structural polymorphism has thus far accumulated (Eanes, 1987; Aquadro, 1992 for reviews) and this has fuelled speculation that the regulatory variation may be of greater adaptive significance (Singh \& Choudhary, 1989; Dickinson, 1991). However, direct experimental tests

\footnotetext{
${ }^{*}$ Correspondence.
}

of the adaptive significance of regulatory variation are still few.

The experiments described here screen for adaptive differences associated with both structural and regulatory polymorphisms of the esterase 6 (EST6) enzyme of Drosophila melanogaster. High levels of structural variation have been documented already for EST6, with a total of 21 variants identified by a combination of electrophoretic and thermostability criteria (Cooke \& Oakeshott, 1987; Labate et al., 1989). Although regulatory variation has been less thoroughly studied, heritable threefold differences have been reported for adult male and female EST6 activities among over 40 field-derived lines (Game \& Oakeshott, 1989). Much of the activity variation in both sexes maps to the third chromosome, on which the esterase 6 structural gene (Est6) resides (69AI; Oakeshott et al., 1987) and a substantial proportion of the male variation at least is associated with restriction site polymorphism in the Est 6 promoter (Game \& Oakeshott, 1990). The latter observation implies the existence of polymorphisms with cis-acting effects on promoter function.

One line of evidence that EST6 is involved in an adaptively significant physiological function is the fact 
that no EST6 null variants have been recovered from over 1000 separately extracted third chromosomes from wild populations (Oakeshott et al., 1989). However, the only EST6 polymorphism, structural or regulatory, which has been thoroughly investigated for its adaptive significance is the major EST6-F/EST6-S electrophoretic polymorphism. The distributions of Est $6-F$ and Est6-S allele frequencies in field populations show complementary nonrandom patterns in respect of both latitude and season (Anderson \& Oakeshott, 1984; Oakeshott et al., 1988). Although the seasonal trends are not strong and the latitudinal relationship breaks down in some Chinese populations (Jiang et al., 1989), the repeatability of the latter over wide latitudinal ranges in Australia, North America and Europe and the consistency of its direction with the pattern in the seasonal variation provide strong evidence that the Est6-F and Est6-S alleles are not neutral to natural selection.

Nevertheless, experiments with laboratory populations aimed at tracing the selection down to individual fitness components related to the physiology of the enzyme have met with only limited success. The major pulse of EST6 expression is in the sperm ejaculatory duct of adult males (Richmond et al., 1990 and references therein) and the enzyme is also found in some other tissues throughout development, such as the gut and haemolymph (Healy et al., 1991). However, extensive efforts have failed to find consistent differences between $E s t 6-F$ and $E s t 6-S$ genotypes, either in aspects of reproductive fitness that could be related to the ejaculatory duct expression (Costa, 1989; Oakeshott et al., 1989; Houle, 1990; Richmond et al., 1990; Miekle \& Richmond, 1991) or in aspects of viability or development time that might be related to gut, haemolymph or other aspects of expression (Kojima \& Huang, 1972; Danford \& Beardmore, 1980; Gilbert, 1985).

The only previous study of the adaptive significance of EST6 regulatory polymorphism found that variation in adult male EST6 activities among six wild-derived lines did not map to the Est 6 locus and was unrelated to male mating times and copula durations but was negatively associated with pre-adult development times (Gilbert, 1985). These are intriguing results but difficult to interpret because of the few lines studie and uncertainty about the relevance of adult EST6 activity to pre-adult development.

Here we report heritable threefold differences in larval and pupal EST6 activity levels among 17 fieldderived lines each isoallelic for Est6. These two measures of pre-adult activity are shown to be largely independent of each other and of the adult male and female activity values previously determined for these lines. The two pre-adult activities are then tested for associations with restriction fragment length polymorphisms in the Est 6 region; two insertions located $1.4 \mathrm{kbp} 5^{\prime}$ of the coding region are found to be associated with low larval activity. Finally, assays of juvenile viability and development time reveal that lines with low larval EST6 activity are less fit under the conditions of the test.

\section{Materials and methods}

The study is based on 19 of the 42 third chromosome isoallelic lines compared for adult male and female EST6 activity levels by Game \& Oakeshott (1989). These lines were extracted from a population at Coff's Harbour (N.S.W., Australia) and they have also been characterized for EST6 allozyme status (Cooke et al., 1987) and restriction fragment length polymorphisms (RFLPs) around the Est 6 gene (Game \& Oakeshott, 1990).

The RFLP study revealed three 5 ' insertions among the 19 lines. Here we determine restriction maps for the three insertions, from Southern analysis of genomic DNA digested with seven restriction enzymes and probed with three cloned fragments overlapping the site of insertion (methods of Game \& Oakeshott, 1990). The restriction enzymes are listed in Fig. 1. The three sequences used as probes were the EcoRI, HindIII and Eco RI/HindIII fragments located 0-1.6 $\mathrm{kbp}, 1.1-2.2 \mathrm{kbp}$ and 1.6-3.6 kbp $5^{\prime}$ of the Est6 initiation codon, respectively (Collet et al., 1990; Game \& Oakeshott, 1990).

In the present study EST6 activity has been measured in homogenates of first instar larvae and 2-day pupae. Three or four replicate cultures were assayed for each of these life stages for 17 of the lines (two of the 19 lines ( 2 and 3 in Table 1) being lost before these assays were carried out). Each culture was established by allowing 50 pairs of flies a $1 \mathrm{~h}$ egg-laying period on media (recipe as for the fitness tests below) supplemented with live yeast. Vials were then incubated at $25^{\circ} \mathrm{C}$ and first instar larvae were collected $48 \mathrm{~h}$ later. Puparia were staged by the flotation method of Mitchell \& Mitchell (1964) and collected after developing a further $48 \mathrm{~h}$ at $25^{\circ} \mathrm{C}$. One homogenate was prepared for each life stage from each culture, each homogenate containing 15-45 first instar larvae or 5-10 2-day pupae. Each homogenate was prepared in $0.1 \mathrm{~mL}$ of $0.1 \mathrm{M}$ phosphate buffer $\mathrm{pH} 6.8$, clarified by centrifugation for $10 \mathrm{~min}$ at $15000 \mathrm{~g}$ and stored at $-20^{\circ} \mathrm{C}$ until used. The concentration of protein in each homogenate was determined by the method of Markwell et al. (1978). Aliquots containing $15 \mu \mathrm{g}$ of protein were then assayed for EST6 activity. 
Ins A $(-1.4)$

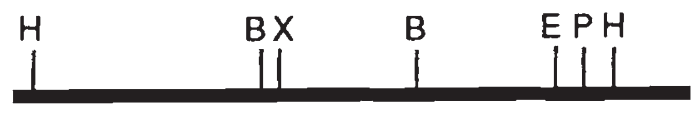

$(6.8 \mathrm{~kb})$

Ins B (-1.4)

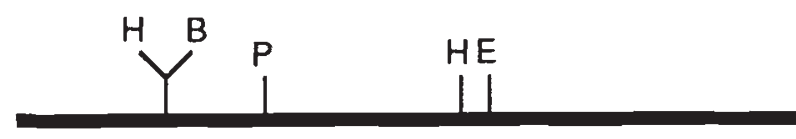

$(8.0 \mathrm{~kb})$

Ins $\mathrm{C}(-1.4)$<smiles>C[C@H](P)CP</smiles>

17.6

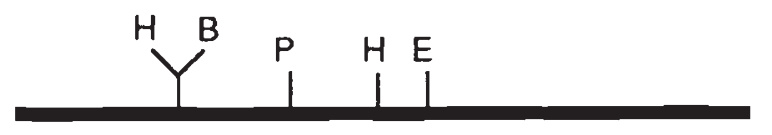

(7.4 kb)

Fig. 1 Restriction maps of Ins $\mathrm{A}(-1.4), \operatorname{Ins} \mathrm{B}(-1.4)$ and Ins $\mathrm{C}(-1.4)$. Restriction enzyme sites were mapped for $\operatorname{Hin}$ dIII $(\mathbf{H}), B g l \mathrm{II}$ (B), $X b a \mathrm{I}(\mathrm{X}), E c o \mathrm{RI}(\mathrm{E})$ and $\operatorname{Pst} \mathrm{I}(\mathrm{P})$. There were no sites for Hpal or SalI. The restriction map of the retrotransposon 17.6 is also shown (from Bingham \& Zachar, 1989).

Table 1 Phenotypes of the 19 lines for EST6 activity (arbitrary units, \pm SEs) in first instar larvae and 2-day pupae, the seven $5^{\prime}$ and two Est6 coding region RFLPs (from Game \& Oakeshott, 1990) and EST6 allozyme status (from Cooke et al., 1987). Haplotypes are also given for the $5^{\prime}(\mathrm{P})$ and coding region $(\mathrm{C})$ polymorphisms, with the coding region haplotypes derived from the two RFLPs and the allozyme data

EST6 polymorphism

\begin{tabular}{|c|c|c|c|c|c|c|c|}
\hline \multirow[b]{2}{*}{ Line } & \multicolumn{2}{|c|}{ EST6 activity } & \multicolumn{2}{|c|}{ Promoter } & \multicolumn{3}{|c|}{ Coding region } \\
\hline & Larvae & Pupae & RFLPs $\dagger$ & Haplotype & RFLPs $\dagger$ & Allozymes & Haplotype \\
\hline 36 & $1.13 \pm 0.06$ & $0.88 \pm 0.14$ & ---+++- & PA & -- & 5 & $\mathrm{CA}$ \\
\hline 44 & $0.72 \pm 0.12$ & $0.84 \pm 0.06$ & -----+- & PB & +- & 1 & $\mathrm{CB}$ \\
\hline 45 & 0.66 & $0.92 \pm 0.15$ & -----+- & PB & +- & 1 & $\mathrm{CB}$ \\
\hline 42 & $0.80 \pm 0.15$ & $1.26 \pm 0.03$ & ---++-+ & PC & +- & 4 & $\mathrm{CC}$ \\
\hline 38 & $0.99 \pm 0.21$ & $0.90 \pm 0.06$ & ---++++ & PD & +- & 4 & $\mathrm{CC}$ \\
\hline 41 & $0.98 \pm 0.11$ & $0.94 \pm 0.10$ & ------- & PE & +- & 4 & $\mathrm{CC}$ \\
\hline 33 & $0.83 \pm 0.14$ & $0.92 \pm 0.13$ & ------ & PE & +- & 5 & $\mathrm{CD}$ \\
\hline 43 & $0.70 \pm 0.12$ & $0.80 \pm 0.16$ & ------- & PE & ++ & 2 & $\mathrm{CE}$ \\
\hline 7 & $0.97 \pm 0.09$ & $1.20 \pm 0.11$ & ------- & PE & ++ & 8 & $\mathrm{CF}$ \\
\hline 18 & $0.89 \pm 0.25$ & $0.84 \pm 0.04$ & ------ & PE & ++ & 8 & $\mathrm{CF}$ \\
\hline 19 & $0.93 \pm 0.10$ & $0.88 \pm 0.18$ & $-\cdots-\cdots$ & PE & ++ & 8 & $\mathrm{CF}$ \\
\hline 20 & $0.95 \pm 0.19$ & $1.01 \pm 0.29$ & ------- & $\mathrm{PE}$ & ++ & 8 & $\mathrm{CF}$ \\
\hline 23 & $1.23 \pm 0.13$ & $0.72 \pm 0.13$ & ------ & PE & ++ & 8 & $\mathrm{CF}$ \\
\hline 25 & $0.78 \pm 0.24$ & $0.87 \pm 0.06$ & ------- & PE & ++ & 8 & $\mathrm{CF}$ \\
\hline $2 \ddagger$ & ND & ND & ------- & PE & ++ & 9 & $\mathrm{CG}$ \\
\hline 32 & $1.15 \pm 0.08$ & $0.85 \pm 0.04$ & --+-++- & PF & ++ & 8 & $\mathrm{CF}$ \\
\hline 16 & $0.36 \pm 0.04$ & $0.42 \pm 0.11$ & -+----- & PG & ++ & 8 & $\mathrm{CF}$ \\
\hline $3 \ddagger$ & ND & ND & +----- & PH & ++ & 9 & $\mathrm{CG}$ \\
\hline 10 & $0.47 \pm 0.14$ & $0.76 \pm 0.09$ & +------ & $\mathrm{PH}$ & ++ & 9 & $\mathrm{CG}$ \\
\hline
\end{tabular}

$\dagger$ In order from left to right, the $5^{\prime} \mathrm{RFLPs}$ are $\operatorname{Ins} \mathrm{A}(-1.4)$, Ins $\mathrm{B}(-1.4)$, Ins $\mathrm{C}(-1.4), \operatorname{Dde} \mathrm{I}(-0.90), \operatorname{Taq} \mathrm{I}(-0.63), \operatorname{Rsa} \mathrm{I}(-0.53)$ and Sau $3 \mathrm{~A}(-0.20)$ and the coding region RFLPs are RsaI $(+0.20)$ and $T a q \mathrm{I}(+0.80)$ (numbers in parentheses indicating distances in $\mathrm{kbp}$ from the initiation codon).

†EST6 activities were not determined for lines 2 and 3; see text. 
There was insufficient EST6 activity in either the larval or pupal extracts to allow assays of EST6 activity by the spectrophotometric procedure of Game \& Oakeshott (1989). Accordingly, EST6 activity was assessed by laser densitometry of the EST6 isozyme band after native polyacrylamide gel electrophoresis and histochemical staining for carboxylesterase activity. Electrophoretic and histochemical methods followed Healy et al. (1991) (including both $\alpha$ - and $\beta$-naphthyl acetate as substrates) and densitometry was carried out in a Shimadzu dual-wavelength scanning densitometer set at $640 \mathrm{~nm}$. Trial experiments confirmed that the relationship between EST6 activity levels and absorbance values was linear under these assay conditions. Four gels each containing homogenates of most of the lines under study were assayed for larvae and five such gels were scored for pupae.

The two components of pre-adult fitness measured were viability and development time from the first instar larval stage to adult eclosion. Both components were measured on about three different test cultures for 18 of the lines. (These included all but one of the 17 lines (45 in Table 1) scored for EST6 activity; line 45 bore an eye colour mutant on chromosome III that could have independently affected fitness.) Larvae to be tested were collected within $24 \mathrm{~h}$ of egg-laying and counted out in lots of not less than 50 , and where possible 100 , per test culture. Test cultures contained either $5.5 \mathrm{~mL}$ medium ('high density cultures') or 10 mL medium ('low density cultures'). The medium comprised $40 \mathrm{~g}$ agar, $400 \mathrm{~mL}$ treacle, $400 \mathrm{~g}$ cornmeal, 750 $\mathrm{g}$ dead yeast and $106 \mathrm{~mL}$ of the fungicide Tegasept (supplier: Bronson \& Jacobs), made up to $4 \mathrm{~L}$ with distilled water. The test vials were incubated at $18 \pm 1^{\circ} \mathrm{C}$ and the adults emerging were counted and removed every day.

All activity and fitness data were analysed by generalized linear modelling procedures (Payne, 1985). Analyses of untransformed data are presented here but essentially similar results were obtained when logarithmically transformed activity data and angularly transformed viability scores were analysed.

\section{Results}

Mean EST6 activities for the 17 lines for which data are available cover a 340 per cent range for larval activity $(0.36 \pm 0.04$ to $1.23 \pm 0.13)$ and a 300 per cent range for pupal activity $(0.42 \pm 0.11$ to $1.26 \pm 0.03$; Table 1). Similar ranges were reported for adult male and female activities among these lines (Game \& Oakeshott, 1989).

To assess the contributions of regulatory and structural differences to the pre-adult activity variation, we have used previously determined RFLP and allozyme data to describe the lines in terms of two sets of haplotypes (Table 1). One set is generated from seven RFLPs in the first three $\mathrm{kbp} 5^{\prime}$ of the gene and the second is generated from two coding region RFLPs plus six allozymic differences. The seven $5^{\prime}$ RFLPs comprise four site polymorphisms $(\operatorname{Dde} \mathrm{I}(-0.90), \quad$ Taq $\mathrm{I}(-0.63)$, $R s a \mathrm{I}(-0.53)$ and $\operatorname{Sau} 3 \mathrm{~A}(-0.20))$ in the $900 \mathrm{bp}$ nearest the coding region and three insertions $(\operatorname{Ins} \mathrm{A}(-1.4)$, $\operatorname{Ins} \mathrm{B}(-1.4)$ and $\operatorname{Ins} \mathrm{C}(-1.4)$ ), which all differ in size but map to the same region $(-1.15$ to $-1.55 \mathrm{kbp})$. Of the two coding region RFLPs, the $R s a \mathrm{I}(+0.20)$ polymorphism is silent but $\operatorname{Taq} \mathrm{I}(+0.80)$ results in a threonine versus alanine difference at residue 247 of the EST6 protein. This polymorphism does not cause an allozyme difference although it is in strong gametic disequilibrium with one (Cooke \& Oakeshott, 1989). The six allozymes in the sample cover four major electrophoretic mobility classes, EST6-vF (otherwise denoted EST6-1), EST6-F' (or EST6-2), EST6-F and EST6-S. The latter two are the more common major mobility classes and each contains two minor mobility variants (EST6-4 and EST6-5, and EST6-8 and EST69, respectively). The TaqI $(+0.80)$ polymorphism is in strong disequilibrium with the EST6-F/EST6-S difference.

The seven coding region haplotypes do not contribute significantly to the activity differences in either stage (Table 2). However, large proportions of the activity variation in both life stages are due to differences among the eight $5^{\prime}$ haplotypes (79 per cent for larvae and 71 per cent for pupae). The two haplotypes contributing most of these differences are PG and PH (lines 16 and 10, respectively), both of which have low larval activities and one of which, PG, is also low for pupal activity. Haplotypes PG and PH are distinct from all others in having the $5^{\prime}$ insertions $\operatorname{Ins} \mathrm{B}(-1.4)$ and Ins $\mathrm{A}(-1.4)$, respectively. These are also the only two polymorphisms that are significantly associated with juvenile activity when all the polymorphisms are analysed individually. Consistent with the haplotype analyses, $\operatorname{Ins} \mathrm{B}(-1.4)$ is associated with both larval and pupal activity and $\operatorname{Ins} \mathrm{A}(-1.4)$ is associated with larval activity (Table 2 ).

Restriction maps for the three insertions, $\operatorname{Ins} \mathrm{A}(-1.4)$, Ins $\mathrm{B}(-1.4)$ and $\operatorname{Ins} \mathrm{C}(-1.4)$, were determined with a combination of enzymes and probes that allow significant revision to the previous estimates of their size. We estimate $\operatorname{Ins} \mathrm{A}(-1.4)$ as $6.8 \mathrm{kbp}$, Ins $\mathrm{B}(-1.4)$ as $8.0 \mathrm{kbp}$ and $\operatorname{Ins} \mathrm{C}(-1.4)$ as $0.5 \mathrm{kbp}$ (Fig. 1, cf. 4.9, 0.9 and $0.5 \mathrm{kbp}$ in Game \& Oakeshott, 1990). However, we confirm the previous localization of all three insertions to a region which is between 1.15 and $1.55 \mathrm{kbp} 5^{\prime}$ of the initiation codon. Their similar 
Table 2 Analyses of variance for the effects on estimated larval and pupal EST6 activities due to different gels and lines; then within lines, due to different $5^{\prime}$ or coding region haplotypes; and finally, within $5^{\prime}$ haplotypes, due to different nucleotide polymorphisms

\begin{tabular}{|c|c|c|c|c|}
\hline \multirow[b]{2}{*}{ Source of variation } & \multicolumn{2}{|c|}{ Larval activity } & \multicolumn{2}{|c|}{ Pupal activity } \\
\hline & d.f. & $F \dagger$ & d.f. & $F^{\dagger}$ \\
\hline Gels & 3 & $15.2^{* * *}$ & 4 & $13.2^{* * * *}$ \\
\hline Lines & 16 & $1.9 @$ & 16 & $2.0^{*}$ \\
\hline Coding haplotypes & 6 & 1.9 & 6 & 0.9 \\
\hline $5^{\prime}$ haplotypes & 7 & $3.2^{* *}$ & 7 & $3.1 * *$ \\
\hline $\operatorname{Ins} \mathrm{A}(-1.4)$ & 1 & $5.5^{*}$ & 1 & 0.5 \\
\hline $\operatorname{InsB}(-1.4)$ & 1 & $11.2^{* *}$ & 1 & $13.9^{* * *}$ \\
\hline $\operatorname{Ins} \mathrm{C}(-1.4)$ & 1 & 1.5 & 1 & 0.5 \\
\hline $\operatorname{Dde} \mathrm{I}(-0.90)$ and & & & & \\
\hline $\operatorname{TaqI}(-0.63) \ddagger$ & 1 & 0.3 & 1 & 1.3 \\
\hline$R s a \mathrm{I}(-0.53)$ & 1 & 0.2 & 1 & 2.6 \\
\hline $\operatorname{Sau} 3 \mathrm{~A}(-0.20)$ & 1 & 2.8 & 1 & 1.2 \\
\hline
\end{tabular}

$\dagger$ All terms are tested against the residual mean squares (chiefly composed of nonsignificant gel $\times$ line interactions), with 36 and $48 \mathrm{~d}$.f. for larval and pupal activities respectively. $\ddagger D$ de $\mathrm{I}(-0.90)$ and $\operatorname{Taq} \mathrm{I}(-0.63)$ have the same distributions across lines.

$@ P \cong 0.05,{ }^{*} P \leqslant 0.05,{ }^{* *} P \leqslant 0.01,{ }^{* * *} P \leqslant 0.001$.

locations suggest the possibility of a common origin but we could not find any shared restriction fragments between $\operatorname{Ins} \mathrm{A}(-1.4)$ and $\operatorname{Ins} \mathrm{B}(-1.4)(\operatorname{Ins} \mathrm{C}(-1.4)$ is too small for meaningful comparisons). If Ins $\mathrm{A}(-1.4)$ and $\operatorname{Ins} \mathrm{B}(-1.4)$ have had a common origin, then one or both must therefore have undergone multiple rearrangements or mutations (in addition to the insertion/deletion(s) which explain their difference in size). The restriction map of $\ln s \mathrm{~B}(-1.4)$ is very similar to that for the $7.4 \mathrm{kbp}$ retrotransposon 17.6 but Ins $\mathrm{A}(-1.4)$ bears no obvious relationship to any known transposable element (Bingham \& Zachar, 1989). However, internally rearranged forms of 17.6 are known to occur at relatively high frequencies (Bingham \& Zachar, 1989), so it remains possible that Ins $\mathrm{A}(-1.4)$ is derived from $\operatorname{In} s \mathrm{~B}(-1.4)$.

Although line 16, bearing the $8.0 \mathrm{kbp} \operatorname{Ins} \mathrm{B}(-1.4)$, is the lowest for both larval and pupal activities, the two activity measures are only weakly correlated across all 17 lines (Table 3). Likewise neither measure is strongly correlated with the adult male or female activity estimates for these lines obtained by Game \& Oakeshott (1989). Thus, while correlations among the four measures are generally positive, they are all small and nonsignificant.

Data on pre-adult development time have been obtained for 18 lines and viability data for 17 lines
Table 3 Correlation coefficients among the 17 line means for larval and pupal EST6 activities from the present analyses and for the adult male and female EST6 activities of these lines in Game \& Oakeshott (1990)†

\begin{tabular}{lcrc}
\hline & Pupae & Adult ơ $^{*}$ & Adult $९ \wp$ \\
\hline Larvae & 0.40 & 0.22 & 0.37 \\
Pupae & & -0.16 & 0.15 \\
Adult ơ $^{\circ}$ & & & 0.33 \\
\hline
\end{tabular}

$\dagger$ All correlations are nonsignificant in these data, although the correlation between adult male and female activities was significant $(r=0.32, P<0.05)$ in the larger set of 42 lines analysed by Game \& Oakeshott (1990).

Table 4 Line means $( \pm$ SE) for pre-adult development time (in days) and viability (\% survival). Results are given separately for high and low density cultures for development time but not for viability, as density only has significant effects on development time (see Table 5)

\begin{tabular}{rccc}
\hline & \multicolumn{2}{c}{ Development time $\dagger$} & \\
\cline { 2 - 3 } Line & High density & Low density & Viability $\dagger$ \\
\hline 36 & $16.1 \pm 0.2$ & $14.3 \pm 0.2$ & $81.1 \pm 3.2$ \\
44 & 16.0 & - & - \\
42 & $17.1 \pm 0.1$ & $16.1 \pm 0.1$ & $72.5 \pm 11.7$ \\
38 & $15.3 \pm 0.1$ & $13.2 \pm 0.2$ & $67.4 \pm 3.2$ \\
41 & $16.1 \pm 0.1$ & $14.2 \pm 0.1$ & $89.7 \pm 3.8$ \\
33 & 15.9 & $14.3 \pm 0.3$ & $66.2 \pm 7.2$ \\
43 & $16.0 \pm 0.2$ & $15.2 \pm 0.1$ & $80.0 \pm 3.5$ \\
7 & $15.4 \pm 0.4$ & $14.6 \pm 0.3$ & $85.9 \pm 2.4$ \\
18 & $16.2 \pm 0.5$ & $14.6 \pm 0.4$ & $64.5 \pm 8.5$ \\
19 & $15.0 \pm 0.3$ & $14.1 \pm 0.4$ & $75.5 \pm 2.6$ \\
20 & $18.4 \pm 0.6$ & $16.4 \pm 0.1$ & $68.9 \pm 2.7$ \\
23 & $15.7 \pm 0.1$ & $14.6 \pm 0.1$ & $78.5 \pm 2.1$ \\
25 & $16.0 \pm 0.5$ & $15.6 \pm 0.2$ & $47.7 \pm 15.2$ \\
2 & $15.1 \pm 0.2$ & $13.6 \pm 0.1$ & $75.2 \pm 2.2$ \\
32 & $15.9 \pm 0.4$ & $13.7 \pm 0.2$ & $78.9 \pm 3.0$ \\
16 & $16.1 \pm 0.2$ & $15.2 \pm 0.2$ & $74.0 \pm 3.4$ \\
3 & $17.2 \pm 0.9$ & $15.4 \pm 0.2$ & $61.5 \pm 5.0$ \\
10 & $17.3 \pm 0.0$ & $16.7 \pm 0.4$ & $57.8 \pm 4.2$ \\
\hline
\end{tabular}

Lines are ordered according to haplotypes as in Table 1. $\dagger$ No fitness data were collected for line 45 (haplotypes PB/ $\mathrm{CB}$ ) because it carried an eye colour mutation that might independently affect fitness.

(Tables 4 and 5). Both fitness measures are estimated at two culture densities but the density difference shows no significant main effect or interaction with line differences in respect of viability. Higher densities significantly retard development time but again there is no significant interaction effect of culture density and lines on development time. There is thus a strong correlation $\left(r_{15}=0.82, P<0.001\right)$ among development times 
Table 5 Analyses of variance for the effects on pre-adult development time and viability due to different culture densities, different lines and, within lines, different EST6 allozyme and EST6 activity values

\begin{tabular}{lrrrrrr}
\hline & \multicolumn{2}{c}{$\begin{array}{c}\text { Development } \\
\text { time }\end{array}$} & & \multicolumn{2}{c}{ Viability } \\
\cline { 2 - 3 } \cline { 6 - 7 } Source of variation & d.f. & $F^{*}$ & & d.f. & $F \dagger$ \\
\hline Density & 1 & $153.2^{* * *}$ & & 1 & 0.1 \\
Density $\times$ lines & 16 & 1.4 & & 13 & 0.4 \\
Lines & 17 & $15.6^{* * *}$ & & 16 & $4.2^{* * *}$ \\
$\quad$ Allozymes & 5 & $3.5^{* *}$ & & 4 & $3.2^{*}$ \\
Larval EST6 activity & 1 & $30.3^{* * *}$ & & 1 & $8.2^{* *}$ \\
Pupal EST6 activity & 1 & 4.0 & & 1 & 1.6 \\
\hline
\end{tabular}

$\dagger$ All terms are tested against the residual, within-line mean squares, with 56 and 42 d.f. for development time and viability, respectively.

${ }^{*} P \leqslant 0.05,{ }^{* *} P \leqslant 0.01,{ }^{* * *} P \leqslant 0.001$.

at the two densities. Development time and viability are not strongly correlated $\left(r_{15}=-0.36, P>0.05\right)$, indicating that the variation in these two measures reflects largely independent effects on fitness.

Highly significant variation among lines is found for both development time and viability, with about a three and a half day difference between the most extreme lines for development time $(13.2 \pm 0.2$ to $16.7 \pm 0.4$ days in low density cultures and $15.0 \pm 0.3$ to $18.4 \pm 0.6$ days in high density cultures $)$ and nearly twofold differences in viability $(47.7 \pm 15.2$ per cent to $89.7 \pm 3.8$ per cent). Significant proportions of the variation among lines for both development time and viability are explained by differences in larval EST6 activity values and EST6 allozyme status but not by differences in pupal EST6 activity values.

The significant effects of larval EST6 activity on the fitness measures reflect a positive association between activity and viability and a negative association between activity and development time (Fig. 2). The most extreme EST6 activity lines, 16 and 10, bearing Ins $\mathrm{B}(-1.4)$ and Ins $\mathrm{A}(-1.4)$, respectively, are major contributors to these effects (analyses excluding these lines give $P>0.05$ for both measures). Independent evidence for the adverse fitness effects of $\operatorname{In} s \mathrm{~B}(-1.4)$ at least comes from line 3, which had been lost before the pre-adult EST6 activity assays were carried out; line 3 closely resembles the other insertion-bearing lines in having slow development and low viability.

Allozyme status is also associated with differences in development time and viability. Most of the fitness differences among the allozyme classes are due to the slower development and lower viabilities of the three
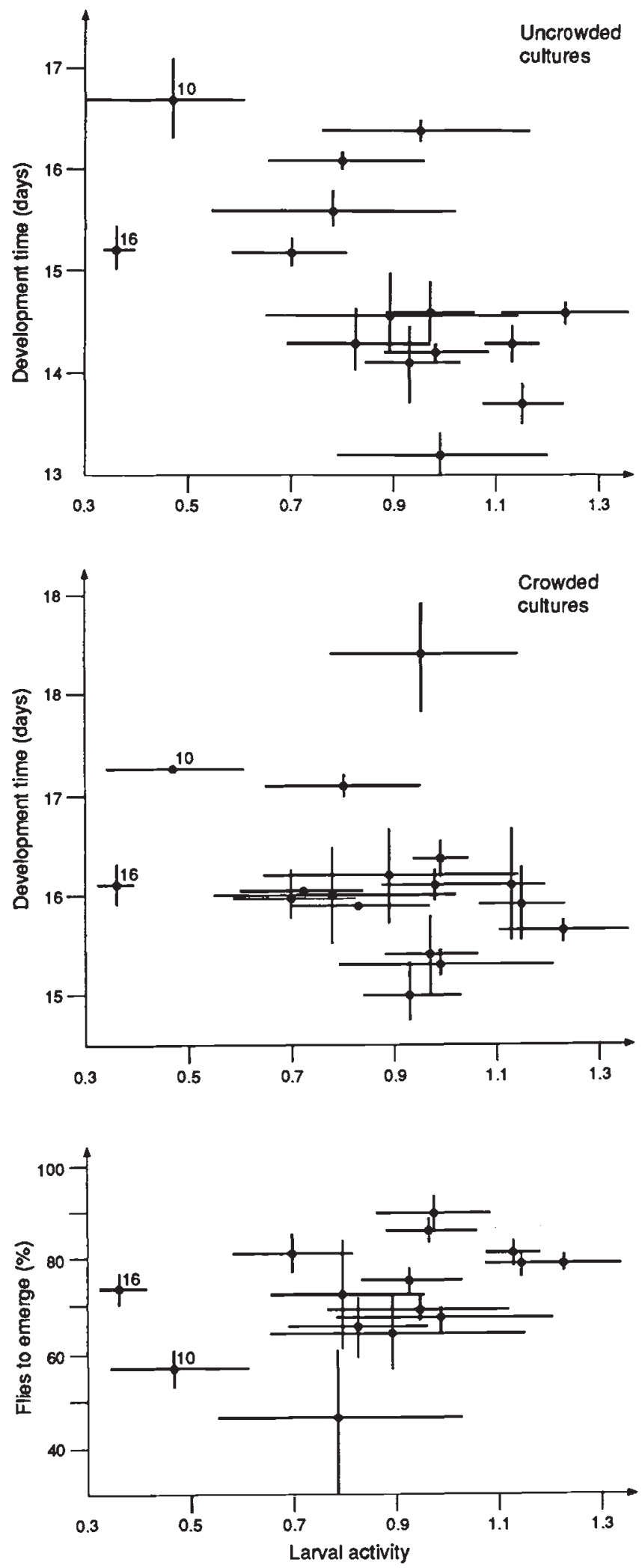

Fig. 2 Relationships of larval EST6 activities with pre-adult development times and viabilities. Lines 10 and 16 , which carried Ins $\mathrm{A}(-1.4)$ and $\operatorname{Ins} \mathrm{B}(-1.4)$, respectively, are indicated. 
Table 6 Allozyme means $( \pm S E)$ for pre-adult development time (days) and viability (\% survival)

\begin{tabular}{cccccc}
\hline \multicolumn{2}{c}{ Allozyme } & & \multicolumn{2}{c}{ Development time } & \\
\cline { 1 - 1 } Major & Minor & & High density & Low density & Viability \\
\hline EST6-VF & EST6-1 & 16.0 & - & - \\
EST6-F' $^{\prime}$ & EST6-2 & & $16.0 \pm 0.1$ & $15.2 \pm 0.1$ & $80.8 \pm 3.5$ \\
EST6-F & EST6-4 & & $16.0 \pm 0.3$ & $14.5 \pm 0.4$ & $78.4 \pm 4.1$ \\
& EST6-5 & & $16.0 \pm 0.4$ & $14.3 \pm 0.2$ & $73.7 \pm 4.6$ \\
EST6-S & EST6-8 & & $16.2 \pm 0.3$ & $14.8 \pm 0.2$ & $73.4 \pm 2.2$ \\
& EST6-9 & & $16.5 \pm 0.5$ & $15.1 \pm 0.5$ & $65.9 \pm 3.0$ \\
\hline
\end{tabular}

EST6-9 lines within the major EST6-S class (Table 6). However two of these three EST6-9 lines also bear Ins $\mathrm{B}(-1.4)$ (Table 1). While these two lines ( 3 and 16$)$ have low viability and slow development, the third EST6-9 line (2) does not. We conclude that the apparent effect of EST6-9 on viability and development is not a causal relationship but simply a consequence of the association between EST6-9 and $\operatorname{Ins} \mathrm{B}(-1.4)$ in two of the three relevant lines.

Gilbert (1985) had previously reported a preliminary analysis testing for a relationship between EST6 activity and development time among six lines of $D$. melanogaster. No pre-adult EST6 activity data were available for his experiment but a significant negative relationship between development time and adult male EST6 activity was detected. The present study allows a more comprehensive test for this relationship. No relationship between the adult male EST6 activity values of Game \& Oakeshott (1989) and the pre-adult development time data from this study is evident among the 16 lines for which both measures are available $\left(F_{1,56}=2.50, P>0.05\right)$.

\section{Discussion}

Substantial heritable variation for larval and pupal EST6 activities has been detected among 17 third chromosome isoallelic lines extracted from a single natural population of $D$. melanogaster. The results concur with those of Game \& Oakeshott (1989) who found large heritable EST6 activity differences among these lines in the EST6 activity of adults. Game \& Oakeshott (1989) found that the variation in adult activity was only weakly correlated across the two sexes. Similarly, we find only weak correlations between larval and pupal activity and between larval activity and adult female activity, with effectively negligible associations between larval and adult male activities and between pupal activity and either adult measure. There is thus largely independent genetic control of variation in the four measures of EST6 activity.

A comparison of the nucleotide polymorphisms associated with the activity variation likewise indicates distinct genetic bases for the variation in the four measures. Game \& Oakeshott (1990) showed that about half the adult male activity variation was associated with differences in $5^{\prime}$ haplotypes and about half of this association was due to the RsaI $(-0.53)$ polymorphism. However, they found no significant correlations between adult female activity variation and nucleotide polymorphisms in either the $5^{\prime}$ or coding regions. Here we find associations with $5^{\prime}$ haplotypes for larval and pupal activities which are due to $\operatorname{Ins} \mathrm{A}(-1.4)$ and, in particular, $\operatorname{Ins} \mathrm{B}(-1.4)$ and which are associated with twofold reductions in pre-adult EST6 activity.

There are several ways of explaining the insertion/ activity associations we have detected but we favour those which invoke effects on EST6 expression mediated by changes to Est6 promoter function. Explanations invoking effects on EST6 structure seem less likely because no stage-specific structural differences have been described for EST6 to date (Healy et al., 1991 and references therein). Explanations based on structural effects would also require that the insertions are not themselves causally involved in the associations but in linkage disequilibrium with causal replacement polymorphisms in the Est6 coding region. However, such disequilibrium in itself is not unlikely. One pertinent example is the association between Ins $\mathrm{B}(-1.4)$ and EST6-9 among the lines studied here. Game \& Oakeshott (1990) also showed high levels of disequilibrium among a number of nucleotide polymorphisms up to 1-2 kbp apart in the Est6 region.

One of three other explanations that we consider more likely than structural effects also assumes that Ins $\mathrm{A}(-1.4)$ and $\operatorname{In} s \mathrm{~B}(-1.4)$ have no causal effect but are in linkage disequilibrium with other, unscored, causal polymorphisms, this time in the Est6 promoter. Game \& Oakeshott (1990) calculated that their RFLP survey effectively only screened about 10 per cent of the sites in the first kbp of $5^{\prime}$ DNA and even less in the next kbp. There is thus considerable scope for more polymorphisms to exist in $5^{\prime}$ regions likely to contain promoter elements.

The other two explanations we consider likely both invoke a causal involvement of $\operatorname{Ins} \mathrm{A}(-1.4)$ and Ins $\mathrm{B}(-1.4)$ in their activity associations. In one case, the reduction in activity could be a direct consequence of the disruption of specific pre-adult promoter element(s) located at the insertion site(s). Alternatively it could be an indirect effect resulting from interference in the transcription of Est 6 in pre-adults by transcription of the inserted material at this stage. 
The possibility that $\operatorname{In} s \mathrm{~A}(-1.4)$ and $\operatorname{Ins} \mathrm{B}(-1.4)$ directly disrupt pre-adult promoter elements is consistent with the results of functional studies on germ-line transformants bearing Est6 genes variously truncated in their $5^{\prime}$ regions. Most aspects of Est6 expression prove to be inherited in the first kilobase pair of $5^{\prime}$ DNA (Karotam \& Oakeshott, 1993; Ludwig et al., 1993) but control of pre-adult expression is also exercised by elements outside this region, which could include the insertion site $(\mathrm{s})$ for $\operatorname{Ins} \mathrm{A}(-1.4)$ and Ins $\mathrm{B}(-1.4)$ (M.J.H., M.M. Dumancic, A. Cao \& J.G.O., unpublished data). In this scheme, the failure of Ins $\mathrm{C}(-1.4)$ to disrupt Est6 expression might be explained most simply by Ins $\mathrm{C}(-1.4)$ having a different insertion site which does not disrupt a specific control element.

The other possibility, that $\operatorname{Ins} \mathrm{A}(-1.4)$ and Ins $\mathrm{B}(-1.4)$ indirectly interfere with Est 6 transcription, presumes that the two insertions are themselves transcriptionally active in pre-adult tissue. We do not know whether this occurs but somatic transcription has been reported for the retrotransposon 17.6, which resembles $\operatorname{Ins} \mathrm{B}(-1.4)$ in its restriction map (Bingham \& Zachar, 1989). Moreover there are precedents for interference in the transcription of adjacent genes by transcription of other Drosophila retrotransposons. For example, Strand \& McDonald (1989) described a naturally occurring alcohol dehydrogenase $(A d h=$ gene; $\mathrm{ADH}=$ enzyme) variant in $D$. melanogaster which has aberrantly low pre-adult $\mathrm{ADH}$ activity levels and contains a copia transposable element inserted in the same orientation as the $A d h$ gene about $300 \mathrm{bp}$ upstream of the $A d h$ promoter. The copia element is maximally transcribed in pre-adults and it was proposed that this upstream transcriptional activity interferes with the function of the $A d h$ promoter. A parallel interpretation of our own data might assume that $\operatorname{Ins} \mathrm{B}(-1.4)$ is indeed a transcriptionally active form of 17.6 and that Ins $\mathrm{A}(-1.4)$ has been derived from Ins $\mathrm{B}(1.4)$ by a rearrangment(s) which does not prevent its transcription (at least in larvae), but that the large deletion(s) involved in obtaining $\operatorname{Ins} \mathrm{C}(-1.4)$ has largely abolished transcriptional activity.

Whatever their molecular bases, the EST6 activity associations we report here for $\operatorname{Ins} \mathrm{A}(-1.4)$ and Ins $\mathrm{B}(-1.4)$ add to a growing body of data indicating that $5^{\prime}$ insertions can change gene expression. Like most of the other examples, the present data indicate a decrease in activity (see e.g. Bingham \& Zachar, 1989; Gibson et al., 1992), but there are also some instances where promoter activity is apparently enhanced (Laurie et al., 1992; Mathew et al., 1992) or changed in its tissue specificity (Parkhurst \& Corces, 1986). While promoter polymorphisms involving single base changes have also been implicated in altered expression levels (e.g. the $R s a \mathrm{I}(-0.53)$ polymorphism and adult male EST6 levels; Game \& Oakeshott, 1990), it is evident that insertional polymorphisms may be significant sources of naturally occurring variation in promoter function.

In the case of Est6, we have also found evidence that this variation in promoter function may affect fitness. Specifically, larval EST6 activity is positively associated with fitness as assessed from development time and pre-adult viability. Moreover, this effect is explained by the lower fitness of the low activity lines bearing $\operatorname{Ins} \mathrm{A}(-1.4)$ and $\operatorname{Ins} \mathrm{B}(-1.4)$. There remains some possibility that these insertion-fitness associations may not be mediated by effects of the insertions on EST6 activity but by their effects on the functioning of the next transcriptional unit upstream. We do not know the physiological function of this adjacent gene but as its $3^{\prime}$ end is several hundred base pairs upstream of the insertion sites (Collet et al., 1990), it is less likely to be affected by the insertions than is Est6. We also note that an Est6-mediated effect is consistent with the dietary or detoxifying roles of the enzyme inferred from its localization in larval gut and haemolymph (Healy et al., 1991).

The fitness tests herein also reveal an association due to EST6 allozyme status; flies bearing EST6-9 within the major EST6-S class show slower development and lower viability than flies bearing the other five allozymes tested. However, this effect appears to be a consequence of an association between EST6-9 and $\operatorname{Ins} \mathrm{B}(-1.4)$ in two of the three EST6-9 lines studied; the third EST6-9 line does not carry $\operatorname{Ins} \mathrm{B}(-1.4)$ and does not show the effect. We draw three conclusions from these findings. Firstly, we note that EST6-9 is much less common than the other EST6-S variant, EST6-8 (Labate et al., 1989), so the EST6-9 differences have little explanatory value for the latitudinal clines and seasonal variation for the major EST6-S and EST6-F classes (Anderson \& Oakeshott, 1984). Secondly, the association of EST6-9 with reduced fitness (even though not causal) shows the importance of complete ascertainment of structural variation in any fitness comparisons among allozyme genotypes. Previously such comparisons have not distinguished among the many minor mobility variants within EST6-F and EST6-S. Our finding may help explain some puzzling discrepancies among studies (reviewed in Oakeshott et al., 1989; Richmond et al., 1990 and see also Costa, 1989; Houle, 1990; Miekle \& Richmond, 1991). Thirdly, our data testify to the dangers of ascribing causality to fitness associations between allozymes (or any other variation) without screening for closely linked polymorphisms which may 
be in disequilibrium with them. In our case the ascertainment of flanking variation over just a few kbp changes our interpretation of the mechanistic bases for the EST6-9 differences to the point where we are left with no evidence for causal fitness associations among the various EST6 allozymes but clear indications of the adaptative significance of regulatory variation at the locus.

\section{Acknowledgements}

We thank Anh Cao, Mira Dumancic and Eric Hines for excellent technical assistance, Thomas Boyce for help with the statistics and him and Robyn Russell for valuable comments on the manuscript.

\section{References}

ANDERSON, P. R. AND OAKESHOTT, J. G. 1984. Parallel geographic patterns of allozyme variation in two sibling Drosophila species. Nature, 308, 729-731.

AQUADRO, C. F. 1992. Molecular population genetics of Drosophila. In: Oakeshott, J. G. and Whitten, M. J. (eds) Molecular Approaches to Fundamental and Applied Entomology, pp. 222-266. Springer-Verlag, New York.

BINGHAM, P. M. AND ZACHAR, z. 1989. Retrotransposons and the FB transposon from Drosophila melanogaster. In: Berg, D. and Howe, M. M. (eds) Mobile DNA, pp. 485-502. American Society for Microbiology, Washington DC.

COLLET, C., NIELSEN, K. M., RUSSELL, R. J., KARL, M., OAKESHOTT, J. G. AND RICHMOND, R. C. 1990. Molecular analysis of duplicated esterase genes in Drosophila melanogaster. Mol. Biol. Evol., 7, 9-28.

COOKE, P. H. AND OAKESHOTT, J. G. 1989. Amino acid polymorphisms for esterase-6 in Drosophila melanogaster. Proc. Natl. Acad. Sci. U.S.A., 86, 1426-1430.

COOKE, P. H., RICHMOND, R. C. AND OAKESHOTT, J. G. 1987. High resolution electrophoretic variation at the esterase- 6 locus in a natural population of Drosophila melanogaster. Heredity, 59, 259-264.

COSTA, R. 1989. Esterase 6 and the pheromonal effects of cisvaccenyl acetate in Drosophila melanogaster. J. Evol. Biol., 2, 395-407.

DANFORD, N. D. AND BEARDMORE, J. A. 1980. Selection at the esterase-6 locus in Drosophila melanogaster by added enzyme substrates in the culture medium. Genetica, 51, 171-178.

DICKINSON, w. J. 1991. The evolution of regulatory genes and patterns in Drosophila. In: Hecht, M. K., Wallace, B. and MacIntyre, R. J. (eds) Evolutionary Biology, vol. 25, pp. 127-173. Plenum Press, New York.

EANES, W. F. 1987. Allozymes and fitness: evolution of a problem. Trends Ecol. Evol., 2, 44-48.

GAME, A. Y. AND OAKESHOTT, J. G. 1989. Variation in the amount and activity of esterase 6 in a natural population of Drosophila melanogaster. Heredity, 62, 27-34.

GAME, A. Y. AND OAKESHOTT, J. G. 1990. Associations between restriction site polymorphism and enzyme activity varia- tion for esterase 6 in Drosophila melanogaster. Genetics, 126, 1021-1031.

GIBSON, J. B., WILKS, A. V. AND AGRotis, A. 1992. Molecular relationships between alcohol dehydrogenase null-activity alleles from natural populations of Drosophila melanogaster. Mol. Biol. Evol., 9, 250-260.

GILBERT, D. 1985. Estimating single gene effects on quantitative traits. 1. A diallel method applied to Est 6 in $D$. melanogaster. Theor. Appl. Genet., 69,625-629.

HEALY, M. J., DUMANCIC, M. M. AND OAKESHOTT, J. G. 1991. Biochemical and physiological studies of soluble esterases from Drosophila melanogaster. Biochem. Genet., 29, 365-388.

Houle, D. 1990. Allozyme-associated heterosis in Drosophila melanogaster. Genetics, 123, 789-801.

JIANG, C., GIBSON, J. B. AND CHEN, H. 1989. Genetic differentiation in populations of Drosophila melanogaster from the People's Republic of China: comparison with patterns on other continents. Heredity, 62, 193-198.

KAROTAM, J. AND OAKESHOTT, J. G. 1993. Regulatory aspects of esterase 6 activity variation in sibling Drosophila species. Heredity, 7 1, 41-50.

KOJIMA, K. AND HUANG, S. L. 1972. Effects of population density on the frequency-dependent selection in the esterase- 6 locus of Drosophila melanogaster. Evolution, 26, 313-321.

LABATE, J., BORTOLI, A., GAME, A. Y., COOKE, P. H. AND OAKESHOTT, J. G. 1989. The number and distribution of esterase 6 alleles in populations of Drosophila melanogaster. Heredity, 63, 203-208.

LAURIE, C. C., BRIDGHAM, J. T. AND CHOUdHARY, M. 1992. Associations between DNA sequence variation and variation in expression of the $A d h$ gene in natural populations of Drosophila melanogaster. Genetics, 129, 489-499.

LUDW1G, M. Z., TAMARINA, N. A. AND RiCHMOND, R. C. 1993. Localisation of sequences controlling the spatial, temporal and sex-specific expression of the esterase 6 locus in Drosophila melanogaster adults. Proc. Natl. Acad. Sci. U.S.A., 90, 6233-6237.

MARKWELL, M. A. K., HAAS, S. M., BIEBER, L. L. AND TOLBERT, N. E. 1978. A modification of the Lowry procedure to simplify protein determination in membrane and lipoprotein samples. Analyt. Biochem., 87, 206-210.

MATHEW, P., AGROTIS, A., TAYLOR, A. C. AND McKECHNIE, S. W. 1992. An association between $\mathrm{ADH}$ protein levels and polymorphic nucleotide variation in the $A d h$ gene of Drosophila melanogaster. Mol. Biol. Evol., 9, 526-536.

MIEKLE, D. B. AND RICHMOND, R. C. 1991. Temperature and sexspecific differences in reproduction related to genotypic variation at the esterase6- locus in Drosophila melanogaster. Am. Nat., 138, 762-767.

MITCHELL, H. K. AND MITCHELL, A. 1964. Mass culture and age selection in Drosophila. Dros. Inf. Serv., 39, 135-137.

OAKESHOTT, J. G., COLLET, C., PHILLIS, R. W., NIELSEN, K. M., RUSSELL, R. J., CHAMBERS, G. K., ROSS, V. AND RICHMOND, R. C. 1987. Molecular cloning and characterization of esterase- 6 , a serine hydrolase of Drosophila. Proc. Natl. Acad. Sci. U.S.A., 84, 3359-3363.

OAKESHOTT, J. G., COOKE, P. H., RICHMOND, R. C., BORTOLI, A., GAME, A. Y. AND LABATE, J. 1989. Molecular population genetics of 
structural variants of esterase 6 in Drosophila melanogaster. Genome, 31, 788-796.

OAKESHOTT, J. G., WILSON, S. R. AND KNIBB, W. R. 1988. Selection affecting enzyme polymorphisms in confined populations of Drosophila living in a natural environment. Proc. Natl. Acad. Sci. U.S.A., 85, 293-297.

PARKHURST, S. M. AND CORCES, V. G. 1986. Interactions among the gypsy transposable element and the yellow and suppressor-of-Hairy-wing loci in Drosophila melanogaster. Mol. Cell. Biol., 6, 46-53.

PAYNE, C. D. (ED.) 1985. The Generalised Linear Interactive Modelling System Release 3.77 Manual. Numerical Algorithms Group, Oxford.

RICHMOND, R. C., NIELSEN, K. M., BRADY, J. P. AND SNELLA, E. M.
1990. Physiology, biochemistry and molecular biology of the Est-6 locus in Drosophila melanogaster. In: Barker, J. S. F., Starmer, W. T. and MacIntyre, R. J. (eds) Ecological and Evolutionary Genetics of Drosophila, pp. 273-292. Plenum Press, New York.

SINGH, R. S. AND CHOUDHARY, M. 1989. Evolutionary relationships between gene structure and gene-regulation variation in Drosophila melanogaster. J. Genet., 68, 61-74.

STRAND, D. J. AND McDONALD, J. F. 1989. Location of a copia element $5^{\prime}$ to the Drosophila melanogaster alcohol dehydrogenase gene $(A d h)$ is associated with altered developmental and tissue-specific patterns of expression. Genetics, 121, 787-794. 